PNNL-15947 Rev 0

Erratum

Pacific Northwest

NATIONAL LABORATORY

Proudly Operated by Battelle Since 1965

\title{
Corrosion of Metal Inclusions In Bulk Vitrification Waste Packages
}

\section{Erratum}

\section{September 2016}




\begin{tabular}{|c|c|c|c|}
\hline Date: & September 6, 2016 & Project No.: & \\
\hline To: & PNNL-15947 Rev 0, Erratum & Internal Distribution: & File/LB \\
\hline rom: & Gary L Smith & & \\
\hline Subject: & Erratum & & \\
\hline
\end{tabular}

\section{Erratum}

This report refers to or contains $K_{g}$ values for glasses LAWA44, LAWB45 and LAWC22 affected by calculations errors as identified by Papathanassiu et al. $(2011)^{1}$

The corrected $K_{g}$ values are reported in an erratum included in the revised version of the original report. The revised report can be referenced as follows:

Pierce E. M. et al. (2004) Waste Form Release Data Package for the 2005 Integrated Disposal Facility Performance Assessment. PNNL-14805 Rev. 0 Erratum. Pacific Northwest National Laboratory, Richland, WA, USA.

\footnotetext{
${ }^{1}$ Papathanassiu A. et al. (2011) ILAW Glass Testing for Disposal at IDF: Phase 1 Testing. VSL-11R2270-1. Vitreous State Laboratory, Catholic University of America, Washington, DC, USA.
} 


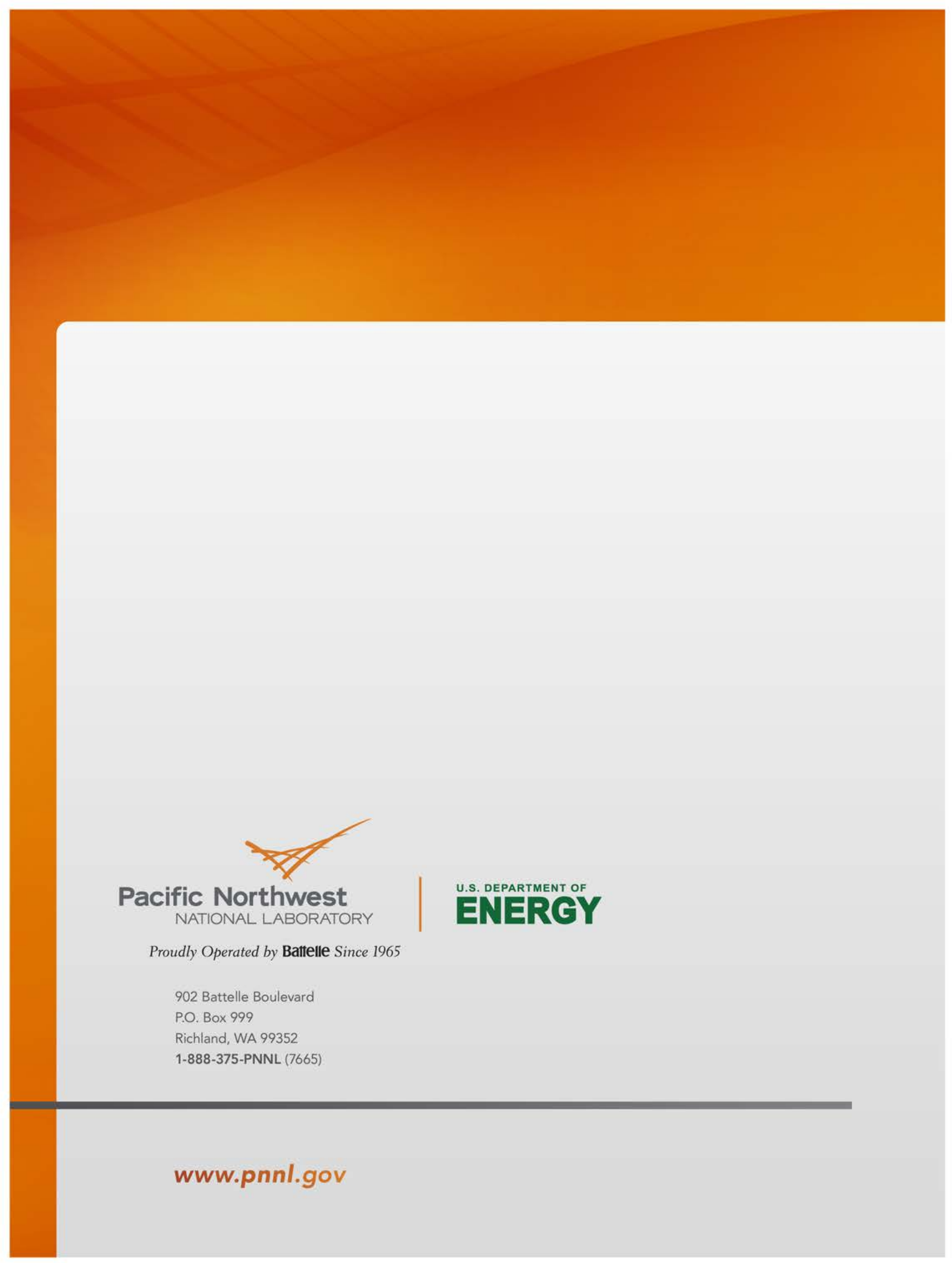

